\title{
Romidepsin for the treatment of relapsed/ refractory peripheral T-cell lymphoma: pivotal study update demonstrates durable responses
}

Bertrand Coiffier ${ }^{1 *}$, Barbara Pro ${ }^{2}$, H Miles Prince ${ }^{3}$, Francine Foss ${ }^{4}$, Lubomir Sokol $^{5}$, Matthew Greenwood ${ }^{6}$, Dolores Caballero ${ }^{7}$, Franck Morschhauser ${ }^{8}$, Martin Wilhelm ${ }^{9}$, Lauren Pinter-Brown ${ }^{10}$, Swaminathan Padmanabhan Iyer ${ }^{11}$, Andrei Shustov ${ }^{12}$, Tina Nielsen ${ }^{13}$, Jean Nichols ${ }^{14}$, Julie Wolfson ${ }^{15}$, Barbara Balser ${ }^{15}$ and Steven Horwitz ${ }^{16}$

\begin{abstract}
Background: Romidepsin is a structurally unique, potent, bicyclic class 1 selective histone deacetylase inhibitor approved by the US Food and Drug Administration for the treatment of patients with cutaneous T-cell lymphoma who have received $\geq 1$ prior systemic therapy and patients with peripheral T-cell lymphoma (PTCL) who have received $\geq 1$ prior therapy. Approval for PTCL was based on results ( $n=130$; median follow-up, 13.4 months) from the pivotal study of romidepsin for the treatment of relapsed/refractory PTCL. The objective is to present updated data (median follow-up, 22.3 months) and to characterize patients who achieved long-term responses $(\geq 12$ months) to romidepsin.
\end{abstract}

Methods: Patients with PTCL who relapsed from or were refractory to $\geq 1$ prior systemic therapy received romidepsin $14 \mathrm{mg} / \mathrm{m}^{2}$ as a 4-hour intravenous infusion on days 1, 8, and 15 every 28 days for up to 6 cycles; patients with response or stable disease could continue romidepsin beyond 6 cycles. The primary endpoint was rate of confirmed/unconfirmed complete response (CR/CRu) determined by an Independent Review Committee. Secondary endpoints included objective response rate (ORR) and duration of response (DOR). For patients who achieved CR/CRu, baseline characteristics by DOR ( $\geq 12$ vs $<12$ months) were examined.

Results: The ORR to romidepsin was 25\%, including 15\% with CR/CRu. The median DOR for all responders was 28 months (range, $<1-48+$ ) and was not reached for those who achieved CR/CRu. Patients with lack of response or transient response to prior therapy achieved durable responses with romidepsin. Of the 19 patients who achieved $\mathrm{CR} / \mathrm{CRu}, 10$ had long-term ( $\geq 12$ months) responses; none of the baseline characteristics examined-including heavy pretreatment, response to prior therapy, or advanced disease-precluded long-term responses to romidepsin. With a median progression-free survival of 29 months, patients who achieved CR/CRu for $\geq 12$ months had significantly longer survival vs those with CR/CRu for $<12$ months or $<$ CR/CRu. Extended treatment and longer follow-up did not affect the reported safety profile of romidepsin.

Conclusions: Treatment with romidepsin leads to highly durable responses in a subset of patients with relapsed/ refractory PTCL, with responses ongoing as long as 48 months.

Trial registration: NCT00426764

Keywords: Romidepsin, Relapsed/refractory peripheral T-cell lymphoma, Duration of response

\footnotetext{
* Correspondence: bertrand.coiffier@univ-lyon1.fr

'Hospices Civils de Lyon, Lyon, France

Full list of author information is available at the end of the article
} 


\section{Background}

Peripheral T-cell lymphoma (PTCL) is an aggressive, uncommon form of non-Hodgkin lymphoma (NHL) that is typically associated with a poor prognosis [1-3]. PTCL comprises many subtypes that vary in morphology, biology, and prognosis [1,2]. The most common subtypes globally are PTCL-not otherwise specified (NOS), angioimmunoblastic T-cell lymphoma (AITL), and anaplastic large cell lymphoma (ALCL) [2]. In western countries, PTCL accounts for $15 \%$ to $20 \%$ of aggressive lymphomas and $5 \%$ to $10 \%$ of NHL diagnoses. The prevalence is higher in Asia, with approximately $15 \%$ to $20 \%$ of all lymphomas classified as PTCL or natural killer/T-cell lymphoma [2,4-6]. Some of this variation may be a result of exposure or genetic susceptibility to pathogenic agents such as human T-lymphotropic virus-1 and Epstein-Barr virus in Asia [2,5,7].

There is no current standard of care for patients with most subtypes of PTCL, and no agents have been approved specifically for use as first-line treatment of PTCL $[3,8]$. In the first line, most patients receive induction chemotherapy regimens derived from studies of B-cell lymphomas, most commonly anthracyclinecontaining regimens such as $\mathrm{CHOP}$ (cyclophosphamide, doxorubicin, vincristine, prednisone) [1-3,8-11]. Although most patients achieve a response with induction chemotherapy, responses are typically brief and many patients experience relapse or become refractory to treatment $[1-3,9,10]$. The role of stem cell transplantation (SCT) for patients with PTCL is yet to be clearly determined and, currently, only a minority $(<20 \%)$ of patients undergo SCT [9-11]. Many patients with PTCL who receive SCT experience disease relapse after transplantation [12].

Romidepsin-a structurally unique, potent, bicyclic class 1 selective histone deacetylase inhibitor [13-15] is approved for the treatment of both patients with cutaneous T-cell lymphoma who have received $\geq 1$ prior systemic therapy and patients with PTCL who have received $\geq 1$ prior therapy [16]. Approval in PTCL was primarily based on results from a phase 2 , single-arm, open-label study in relapsed/refractory PTCL (GPI-060002) [17].

For romidepsin, data from GPI-06-0002 $(\mathrm{n}=130)$ based on an October 2010 cutoff (median follow-up, 13.4 months) were presented in the package insert [16] and published manuscript [17] and include a $25 \%$ objective response rate (ORR), 15\% confirmed/unconfirmed complete response $(\mathrm{CR} / \mathrm{CRu})$ rate, and median duration of response (DOR) of 17 months [17]. As of the October 2010 data cutoff, 17 of 19 patients who had experienced CR/CRu had not progressed [17]. The objective of this manuscript is to present updated GPI-06-0002 efficacy data and characteristics of patients who achieved long-term responses ( $\geq 12$ months) based on a more recent Independent Review Committee
(IRC) assessment (data cutoff, December 31, 2011; median follow-up, 22.3 months).

\section{Results}

\section{Patient characteristics}

A total of 131 patients were enrolled; 130 had histologically confirmed PTCL by central review, and 1 had a diagnosis of diffuse large B-cell lymphoma by central review and was excluded from the baseline measurements and efficacy assessments. Patient demographics and baseline characteristics were previously described in detail $(\mathrm{n}=$ 130) [17]. Briefly, most patients had an Eastern Cooperative Oncology Group (ECOG) performance status of 1 to 2 (64\%), International Prognostic Index $\geq 2(76 \%)$, and stage III or IV disease (70\%). Thirty-six patients $(28 \%)$ had bone marrow involvement. Patients had received a median of 2 (range, $1-8$ ) prior systemic therapies; $37 \%$ of patients had received $\geq 3$ therapies, and $16 \%$ had received prior autologous SCT. The most common PTCL subtypes were PTCL-NOS, AITL, and anaplastic lymphoma kinase (ALK)-1-negative ALCL; baseline characteristics were similar across these common PTCL subtypes.

\section{Efficacy \\ Response rates}

Response rates as assessed by the IRC were unchanged compared with the primary publication [17]: ORR of $25 \%$ (33 of 130), including CR/CRu in $15 \%$ of patients (19 of 130). At a median follow-up of 22.3 months, all patients received a median of 2 treatment cycles (range, $<1-54$ ), whereas patients who achieved a response $(\mathrm{CR} / \mathrm{CRu}$ or partial response $[\mathrm{PR}] ; \mathrm{n}=33$ ) received a median of 8 treatment cycles (range, $<1-54$ ) and patients who achieved a $\mathrm{CR} / \mathrm{CRu}(\mathrm{n}=19)$ received a median of 19 treatment cycles (range, 2-54). Response rates were similar across the 3 most common PTCL subtypes (Table 1), and no significant differences in ORR or rates of $\mathrm{CR} / \mathrm{CRu}$ were observed.

\section{Durability of responses}

Most responses were noted at the first response assessment ( 2 months), and the median time to response as assessed by the IRC was 1.8 months (range, 1.4-5.3 months). The median DOR for all patients who achieved a response by IRC ( $\mathrm{n}=33$ ) was 28 months (range, $<1-48+$ ) and had not been reached (range, $<1-48+$ ) for those who achieved CR/ $\mathrm{CRu}(\mathrm{n}=19)$. One patient with a reported DOR $<1$ month discontinued treatment to receive SCT after the first response assessment of CR. Of the 19 patients who achieved $\mathrm{CR} / \mathrm{CRu}, 53 \%$ had a DOR $\geq 12$ months and $32 \%$ had a $\mathrm{DOR} \geq 24$ months. Responses were durable across the 3 most common PTCL subtypes (Figure 1), and no statistically significant differences in DOR were observed. For patients with progressive disease (PD) to their last prior 
Table 1 Overall Response Rates (IRC)

\begin{tabular}{lccc}
\hline Best response, $\mathbf{n}(\%)$ & $\begin{array}{c}\text { PTCL-NOS } \\
(\mathbf{n = 6 9 )}\end{array}$ & $\begin{array}{c}\text { AITL } \\
(\mathbf{n}=\mathbf{2 7})\end{array}$ & $\begin{array}{c}\text { ALK-1-Negative ALCL } \\
(\mathbf{n}=\mathbf{2 1})\end{array}$ \\
\hline ORR & $20(29)$ & $8(30)$ & $5(24)$ \\
CR/CRu & $10(14)$ & $5(19)$ & $4(19)$ \\
PR & $10(14)$ & $3(11)$ & $1(5)$ \\
SD & $16(23)$ & $9(33)$ & $5(24)$ \\
Disease control (ORR+ SD90) & $34(49)$ & $12(44)$ & $8(38)$ \\
PD/NE & $33(48)$ & $10(37)$ & $11(52)$ \\
\hline
\end{tabular}

Abbreviations: AITL angioimmunoblastic T-cell lymphoma, $A L C L$ anaplastic large cell lymphoma, $A L K$ anaplastic lymphoma kinase, $C R / C R u$ confirmed/unconfirmed complete response, IRC Independent Review Committee, NE not evaluable, ORR objective response rate, $P D$ progressive disease, $P R$ partial response, $P T C L-N O S$ peripheral T-cell lymphoma-not otherwise specified, SD stable disease, SD90 SD for $\geq 90$ days.

${ }^{a}$ Insufficient efficacy data to determine response because of early termination.

therapy $(\mathrm{n}=49)$, the median DOR on romidepsin had not yet been reached for all patients who achieved a response $(\mathrm{n}=14)$ or for patients wxho achieved CR/CRu $(\mathrm{n}=9)$.

Patients with a lack of response $(n=13)$ or transient response $(\mathrm{n}=8$; median DOR, 4.5 months [range, 223 months]) to prior therapy (most commonly CHOP [ $=7$ ], GVD [gemcitabine, vinorelbine, doxorubicin; $n=2$ ], ICE [ifosfamide, carboplatin, etoposide; $\mathrm{n}=2$ ], ESHAP [etoposide, methylprednisolone, high-dose cytarabine, cisplatin; $n=2]$, or pralatrexate [ $n=2]$ ), by investigator assessment, were able to achieve durable $\mathrm{CR} / \mathrm{CRu}$ to romidepsin (median DOR, 14 months [range 1-48+ months]) across the 3 most common PTCL subtypes (Figure 2). Patients who achieved $\mathrm{CR} / \mathrm{CRu}$ with a reported DOR $<12$ months (investigator assessment) discontinued treatment for the following reasons: adverse event $(\mathrm{AE} ; \mathrm{n}=2)$, patient or investigator decision to stop therapy while in $\mathrm{CR}$, physician decision, and SCT (each $\mathrm{n}=1$ ).

\section{Analysis of long-term responders}

Of the 19 patients who achieved CR/CRu (Figure 3), 16 (84\%) had not experienced PD per the IRC at a median follow-up of 25.8 months. For those 16 patients, the DOR at time of censoring ranged from $<1$ month to $48+$ months. Ten of 19 patients who achieved CR/CRu were considered long-term responders (responses $\geq 12$ months). Of these 10 patients, 1 had IRC-confirmed PD; 3 were censored as a result of investigator-assessed PD $(n=1)$, physician decision $(\mathrm{n}=1)$, or $\mathrm{AE}(\mathrm{n}=1)$; and 6 continued romidepsin treatment for $\geq 2$ years (received 25, 27, 29, 36, 36 , and 53 cycles as of the data cutoff). Nine of the 19 patients who achieved $\mathrm{CR} / \mathrm{CRu}$ had a reported $\mathrm{DOR}<12$ months. Two had IRC-confirmed PD, and 7 were censored because investigator-assessed PD $(n=1), \operatorname{SCT}(n=2)$, physician decision $(n=2)$, or patient decision $(n=2)$. None of the baseline characteristics examined-including heavy pretreatment ( $\geq 3$ prior therapies), response to prior therapy, or advanced disease-precluded long-term responses to romidepsin (Table 2).

Achievement of $\mathrm{CR} / \mathrm{CRu}$ was associated with prolonged progression-free survival (PFS; median 29 months) and overall survival (OS; median not reached) compared with patients with a response $<\mathrm{CR} / \mathrm{CRu}$. Furthermore, achievement of $\mathrm{CR} / \mathrm{CRu}$ at $\geq 12$ months was associated with

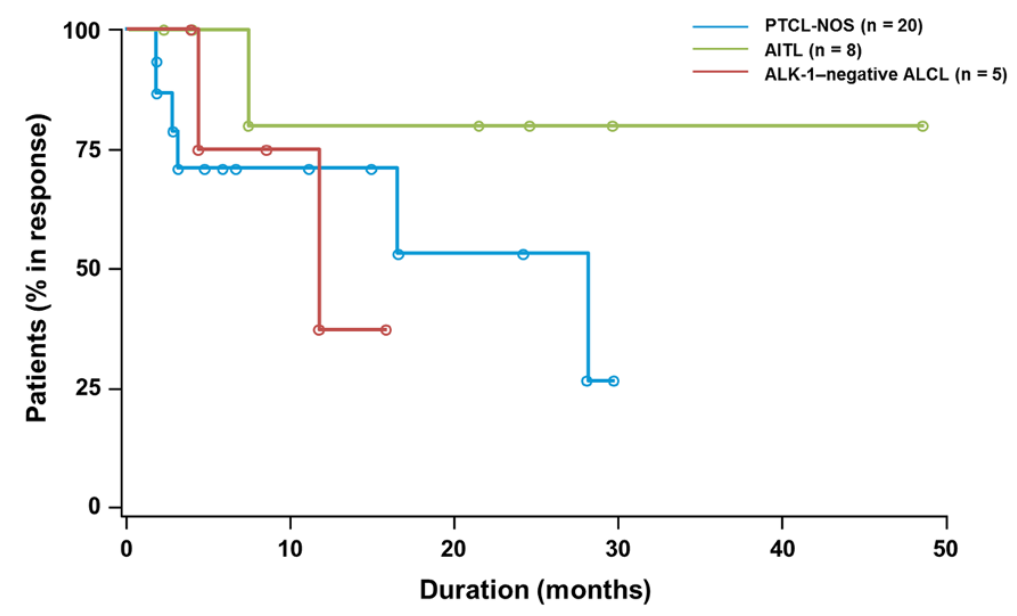

Figure 1 Durations of response for the 3 most common subtypes of PTCL in patients who achieved a response (CR or PR). $\circ$ Indicates a censored patient. 


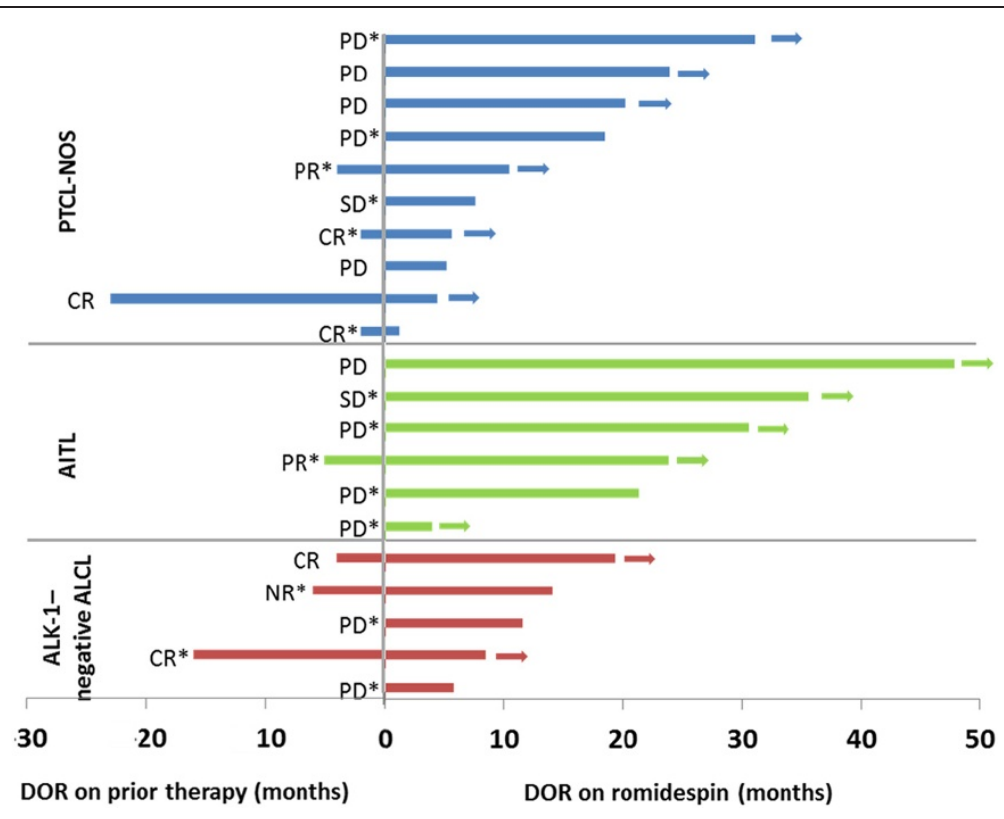

Figure 2 Durations of response for patients who achieved CR/CRu on romidepsin (investigator assessed; $\mathbf{n}=21$ ). Only investigators assessed DOR for prior therapy (for patients with PR or CR on prior therapy). Arrows indicate that the patient was censored while in response. * Indicates that the patient received combination chemotherapy as the last prior therapy. NR indicates that the response to prior therapy was not reported.

prolonged PFS and OS compared with achievement of $\mathrm{CR} / \mathrm{CRu}$ at $<12$ months (Figure 4, Table 3; $\mathrm{P}<.05$ ). Patients who achieved PR or stable disease (SD) for $\geq 90$ days (SD90) had similar long-term outcomes. For all patients, median PFS and OS were 4 months and 11.3 months, respectively.

\section{Safety}

As previously reported, the most common AEs included gastrointestinal disturbances, hematologic abnormalities, asthenic conditions, and infections (all types pooled) [17]. Reported electrocardiogram (ECG) abnormalities were uncommon, with no concurrent symptoms of syncope or other

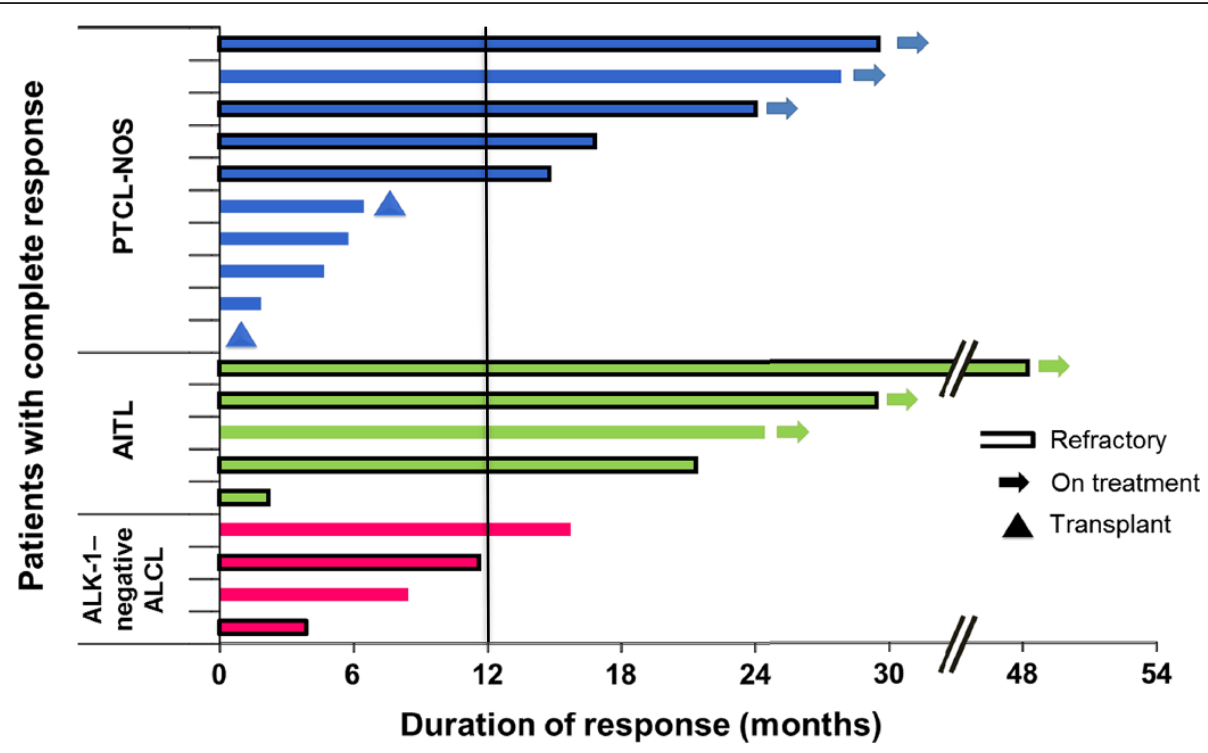

Figure 3 Durations of response for patients who achieved CR/CRu on romidepsin (IRC). The vertical line separates the 10 patients with long-term responses (duration $\geq 12$ months). Of the 2 patients that received stem cell transplant after romidepsin, type of transplant was autologous for 1 patient, and not reported for 1 patient. 
Table 2 Key Baseline Characteristics by Duration of CR/CRu

\begin{tabular}{|c|c|c|c|}
\hline & CR/CRu $\geq 12$ months $(n=10)$ & $\mathrm{CR} / \mathrm{CRu}<12$ months $(\mathrm{n}=9)$ & $P$ value \\
\hline Male sex, n (\%) & $7(70)$ & $5(56)$ & .65 \\
\hline Median age, years (range) & $61.5(47-78)$ & $57.0(37-74)$ & .43 \\
\hline \multicolumn{4}{|l|}{ ECOG performance status, n (\%) } \\
\hline 0 & $3(30)$ & $4(44)$ & \multirow[t]{3}{*}{.57} \\
\hline 1 & $6(60)$ & $3(33)$ & \\
\hline 2 & $1(10)$ & $2(22)$ & \\
\hline \multicolumn{4}{|l|}{ IPI score, n (\%) } \\
\hline$<2$ & $2(20)$ & $1(11)$ & \multirow[t]{2}{*}{1.00} \\
\hline$\geq 2$ & $8(80)$ & $8(89)$ & \\
\hline \multicolumn{4}{|l|}{ Prior systemic therapies, n (\%) } \\
\hline 1 & $2(20)$ & $3(33)$ & \multirow[t]{5}{*}{.38} \\
\hline 2 & $3(30)$ & $3(33)$ & \\
\hline 3 & 0 & $2(22)$ & \\
\hline 4 & $3(30)$ & $1(11)$ & \\
\hline$>4$ & $2(20)$ & 0 & \\
\hline \multicolumn{4}{|c|}{ Best response to most recent prior therapy, n (\%) } \\
\hline CR/CRu/PR & $2(20)$ & $6(67)$ & \multirow[t]{2}{*}{.07} \\
\hline$<P R$ & $8(80)$ & $3(33)$ & \\
\hline \multicolumn{4}{|l|}{ Disease stage at diagnosis, n (\%) } \\
\hline$|/| \mid$ & $0(0)$ & $4(44)$ & \multirow[t]{2}{*}{.03} \\
\hline III/IV & $10(100)$ & $5(56)$ & \\
\hline \multicolumn{4}{|l|}{ PTCL subtype, n (\%) } \\
\hline PTCL-NOS & $5(50)$ & $5(56)$ & \multirow[t]{3}{*}{.34} \\
\hline AITL & $4(40)$ & $1(11)$ & \\
\hline ALK-1-negative ALCL & $1(10)$ & $3(33)$ & \\
\hline Bone marrow involvement, n (\%) & $5(50)$ & $2(22)$ & .35 \\
\hline Elevated LDH, n (\%) & $5(50)$ & $8(89)$ & .14 \\
\hline Platelet count $\times 10^{9} / L$, median (range) & $199(101-307)$ & $172(99-649)$ & .42 \\
\hline
\end{tabular}

Abbreviations: AITL angioimmunoblastic T-cell lymphoma, $A L C L$ anaplastic large cell lymphoma, $A L K$ anaplastic lymphoma kinase, $C R$ complete response, $C R / C R u$ confirmed/unconfirmed complete response, ECOG Eastern Cooperative Oncology Group, IPI International Prognostic Index, LDH lactate dehydrogenase, NOS not otherwise specified, PR partial response, PTCL peripheral T-cell lymphoma.

cardiac AEs at the time of reported ECG abnormality and no clinically significant changes in QT intervals across treatment cycles were found [17]. The AE profile was similar across the 3 most common PTCL subtypes. Longer treatment duration did not affect the safety profile of romidepsin. Grade $\geq 3$ AEs occurred with the highest incidence during cycles 1 to 2 (Figure 5). After cycle 18, $\leq 10$ patients remained on treatment, and most grade $\geq 3$ AEs reported were from 1 patient with grade $\geq 3$ vomiting, cellulitis, deep vein thrombosis, and/or constipation in cycles 22, 24, 27, 31, and 32 . In addition, one patient had grade $\geq 3$ pyrexia in cycle 22 and one patient had grade $\geq 3$ pneumonia in cycle 24 .

\section{Discussion}

Since 2009, 3 agents have been approved in the United States for patients with relapsed/refractory PTCL $[16,18,19]$.
Pralatrexate, a folate analogue, is approved for the treatment of patients with relapsed or refractory PTCL [18] based on a single-arm phase 2 study showing 29\% ORR, including $11 \% \mathrm{CR}(\mathrm{n}=109)$ and a median DOR of 10.1 months [20]. Brentuximab vedotin, a CD30-directed antibody-drug conjugate, is approved for the treatment of patients with systemic ALCL after failure of $\geq 1$ prior multiagent chemotherapy regimen [19]. ALCL is a common subtype of PTCL (approximately 25\% of cases in North America) that is uniformly CD30+ [2,21]. Approval was based on an $86 \%$ ORR, including a $57 \%$ CR $(n=58)$ [21] and a median DOR of 13.2 months [22]. In patients with relapsed/refractory PTCL, romidepsin demonstrated a $25 \%$ ORR, including $15 \% \mathrm{CR} / \mathrm{CRu}$ and a median DOR of 28 months for all responders. Responses were rapid with a median time to objective response of 1.8 months. Long-lasting 


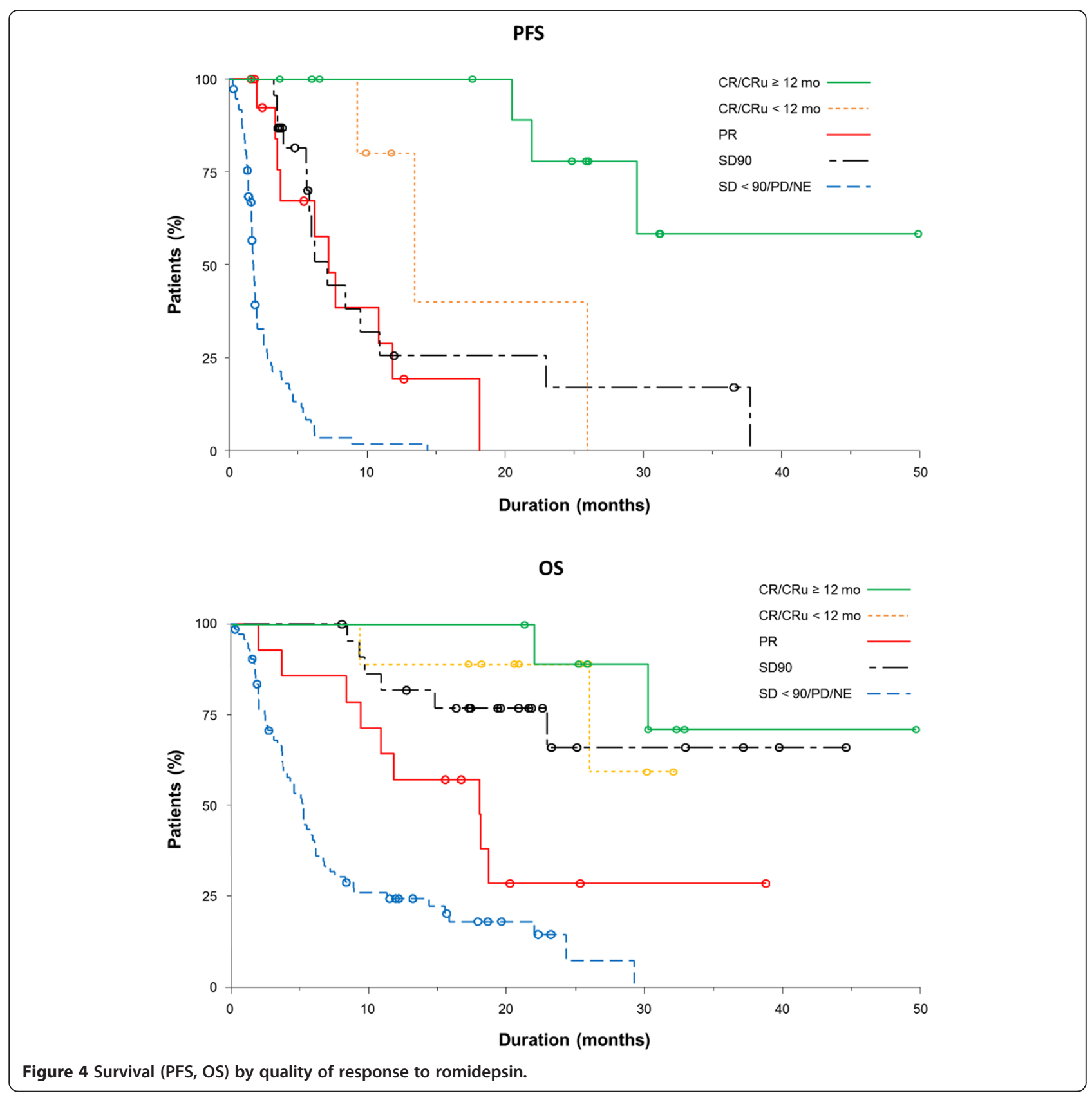

Table 3 Survival (PFS, OS) by Quality of Response to Romidepsin

\begin{tabular}{|c|c|c|c|c|c|c|}
\hline & $\begin{array}{c}\text { Objective } \\
\text { responders } \\
(\mathrm{CR} / \mathrm{CRu}+\mathrm{PR} ; \mathrm{n}=33)\end{array}$ & $\begin{array}{c}\text { CR/CRu } \\
\geq 12 \text { months } \\
(n=10)\end{array}$ & $\begin{array}{c}\text { CR/CRu } \\
<12 \text { months } \\
(n=9)\end{array}$ & $\begin{array}{c}\text { PR } \\
(n=14)\end{array}$ & $\begin{array}{l}\text { SD90 } \\
(n=23)\end{array}$ & $\begin{array}{c}\mathrm{SD}<90 / \\
\mathrm{PD} / \mathrm{NE} \\
(\mathrm{n}=74)\end{array}$ \\
\hline \multirow[t]{2}{*}{ Median OS, months (range) } & 30 & NR & NR & 18 & NR & 5 \\
\hline & $(2.0-49.5)$ & $(21.2-49.5)$ & $(9.2-32.0)$ & $(2.0-38.8)$ & $(8.1-44.6)$ & $(0.3-29.3)$ \\
\hline \multirow[t]{2}{*}{ Median PFS, months, (range) } & 20 & 29 & 13 & 7 & 7 & 2 \\
\hline & $(1.6-49.8)$ & $(17.6-49.8)$ & $(1.6-26.0)$ & $(1.9-18.1)$ & $(3.3-37.7)$ & $(0.3-14.4)$ \\
\hline
\end{tabular}




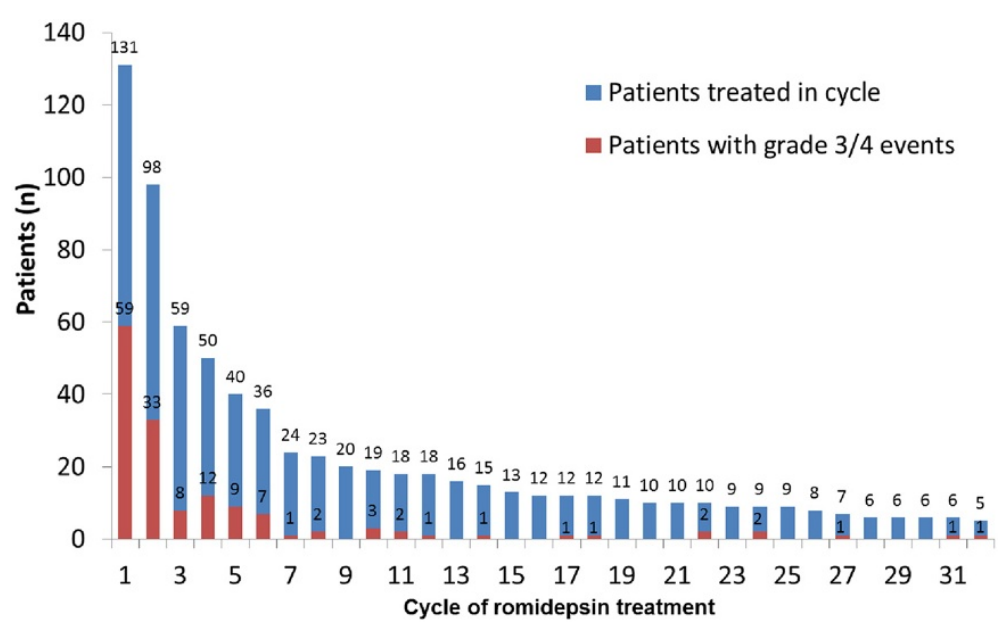

Figure 5 Incidence of grade $\geq 3$ AEs by treatment cycle. Cycles in which no grade $\geq 3$ AEs were reported are not included.

responses occurred across all major PTCL subtypes and in patients refractory to their last prior therapy.

Romidepsin has demonstrated comparable efficacy across the 3 most common PTCL subtypes. Although pralatrexate has general approval for the treatment of PTCL, based on results from the pivotal study in relapsed/refractory PTCL [20], National Comprehensive Cancer Network guidelines report that pralatrexate has demonstrated limited activity in AITL [8]. Brentuximab vedotin has demonstrated considerable activity in ALCL [21], and responses have also been seen in CD30+ cases of other NHL subtypes (including AITL) [23]; however, its utility in non-CD30+ PTCLs is unknown.

More than one-half of the patients with relapsed/refractory PTCL who achieved CR/CRu on romidepsin experienced long-term responses ( $\geq 12$ months). Complete responses were achieved in patients with typically poor prognostic factors, and none of the examined patient or disease characteristics predicted failure to achieve longterm remission. Achievement of $\mathrm{CR} / \mathrm{CRu}$ was associated with prolonged survival, and achievement of SD90 led to survival rates similar to the achievement of PR.

Amendments to the study protocol allowed for maintenance with 2 romidepsin doses per cycle for patients who received $\geq 12$ treatment cycles and with 1 dose per cycle for patients who received $\geq 24$ treatment cycles and had received 2 doses for $\geq 6$ treatment cycles.

Extended dosing of romidepsin was tolerated; the most grade $\geq 3$ AEs were observed in the first 2 cycles of treatment. ECG abnormalities were uncommon, and no clinically significant changes were observed across treatment cycles [17]. An early analysis of a post-marketing QT study demonstrated that romidepsin does not have a concentration-dependent effect on the QTc interval (including at exposures more than 2-fold the approved dosing), and while clinically insignificant changes in QTc were reported, these changes were attributable to antiemetic premedication [24]. Romidepsin was associated with a delayed concentration-dependent increase in heart rate with a maximum mean increase of 20 beats per minute 6 hours after the start of a 4-hour romidepsin infusion [16]. Publication of the final analysis of the QT study is ongoing.

A SEER (Surveillance and Epidemiology End Results) database analysis from 1992 to 2009 showed that, with the exception of ALCL, the incidence of common PTCL subtypes has greatly increased over the past few decades (the combined rate more than tripled from 1992 to 2009) [25]. However, over this same time period, survival times did not increase [25] as they have for patients with B-cell lymphoma [26]. Despite poor outcomes, anthracycline-based regimens continue to be commonly used for the treatment of PTCL [1-3,8-11]. With the approval of 3 novel agents since $2009[16,18,19]$, it is hoped that a trend toward improved survival will begin to emerge. Current studies are evaluating the combination of these newly approved agents with chemotherapeutic regimens. Preliminary results from a phase $1 \mathrm{~B}$ study of romidepsin in combination with $\mathrm{CHOP}$ for the first-line treatment of patients with PTCL (14 evaluable patients) demonstrated an ORR of 78\%, including 57\% CR [27], and a phase 2 extension study is ongoing. A separate phase 3 study of romidepsin $+\mathrm{CHOP}$ vs $\mathrm{CHOP}$ alone in frontline PTCL is also ongoing [28]. Preliminary results from a phase 1 study of brentuximab vedotin with $\mathrm{CH}-\mathrm{P}$ (CHOP minus vincristine) for the first-line treatment of patients with higher-risk systemic ALCL and other CD30+ mature natural killer/T-cell lymphomas $(n=26)$ demonstrated an ORR of $100 \%$, including $88 \%$ CR [29]. A phase 2 study of CEOP (cyclophosphamide, etoposide, vincristine, prednisone) alternating with pralatrexate for the first-line treatment of PTCL is underway [30], and a separate phase 3 study will investigate pralatrexate vs observation maintenance therapy following CHOP-based induction in patients 
with PTCL [31]. Long-term follow-up of these combination trials is essential to determine whether any of these combinations leads to durable responses.

\section{Conclusions}

The results presented herein demonstrate that treatment with single-agent romidepsin leads to highly durable responses in patients with relapsed/refractory PTCL, including patients with the 3 major PTCL subtypes, patients who received several prior systemic therapies, patients with advanced disease, and, importantly, patients refractory to their last prior therapy. Patients with long-term responses to romidepsin can successfully continue on romidepsin, with or without reducing dose frequency, to maintain response at the discretion of the investigator. Whether combining romidepsin with regimens that induce higher initial response rates (eg, $\mathrm{CHOP}$ ) will enhance the durability of these responses and lead to prolonged survival, both in relapsed/refractory patients and in those with newly diagnosed disease, warrants further investigation. Additionally, the potential for use of romidepsin as maintenance therapy after chemotherapy induction or after consolidation with high-dose chemotherapy followed by SCT should be examined, because long-term tolerability has been demonstrated.

\section{Methods}

\section{Study design and eligibility criteria}

GPI-06-0002 is a prospective, single-arm, open-label, international phase 2 study that was previously described in detail [17]. Briefly, eligibility criteria included adult patients with PTCL relapsed or refractory to $\geq 1$ systemic therapy, adequate bone marrow and organ function, and measurable disease according to International Working Group (IWG) criteria [32] and/or measurable cutaneous disease and an ECOG performance status of 0 to 2 at enrollment. Concomitant use of drugs that could significantly prolong the QTc interval was not allowed, and patients with known significant cardiac abnormalities were excluded. Hypokalemia and hypomagnesemia can be associated with ECG abnormalities [33]; therefore, patients must have had serum potassium concentrations $\geq 3.8 \mathrm{mmol} / \mathrm{L}$ and serum magnesium concentrations $\geq 0.85 \mathrm{mmol} / \mathrm{L}$; low levels could be corrected by supplementation to meet inclusion criteria.

Patients received romidepsin $14 \mathrm{mg} / \mathrm{m}^{2}$ (4-hour intravenous infusion) on days 1,8 , and 15 of 28-day cycles (same dose and schedule as those approved for patients with relapsed/refractory cutaneous T-cell lymphoma or PTCL [16]) for up to 6 cycles. Patients with SD or response could continue to receive treatment beyond $6 \mathrm{cy}$ cles at the discretion of the patient and investigator. The protocol was amended to allow for (but not mandate) maintenance dosing of romidepsin (2 doses per cycle) for patients treated for $\geq 12$ cycles. Patients who initiated maintenance dosing must continue to receive $\geq 2$ doses per cycle through at least cycle 24 and must have received 2 doses per cycle for $\geq 6$ months prior to a reduction to 1 dose per cycle.

\section{Response assessments and study endpoints}

The efficacy and safety assessments conducted and the response criteria used were previously described in detail $[17,32]$. Briefly, response assessments were performed every 2 cycles by both investigators and an IRC (composed of both radiologists and hematologic oncologists) according to the 1999 IWG criteria guidelines for response assessments for NHL (IWG-NHL) [32]. The primary endpoint was rate of $\mathrm{CR} / \mathrm{CRu}$ as determined by IRC. Secondary endpoints included ORR, DOR (time from the first date of response to the date of PD or date of last study assessment), and time to disease progression by IRC and investigators' assessments; change in ECOG performance status; tolerability; and safety. Time to response, PFS, and OS were also assessed.

\section{Statistical methods}

This study is ongoing, but December 31, 2011, was the cutoff date for this analysis. Patients who withdrew without PD were to be followed every 2 months until PD, withdrawal from study, or start of alternate therapy. All descriptive statistical analyses were performed by using SAS statistical software version 9.2 (SAS Institute, Cary, NC). Time-to-event data were summarized by Kaplan-Meier methods.

\section{Competing interests}

BC: Celgene Corporation. BP; honoraria: Celgene Corporation. HMP; research grant funding. FF; advisory board: Celgene Corporation. LS; consultancy, speakers bureau: Celgene Corporation; research funding: Gloucester. FM; honoraria: Celgene Corporation. LPB; consultancy: Celgene Corporation. SPI; consultancy: Celgene Corporation. AS; research funding, consultancy, honoraria: Celgene Corporation. TN; employee: Celgene Corporation. JN; employee Jan 2010 - Jul 2012: Celgene Corporation. BB; consultancy: Celgene Corporation. SH; consultancy and grant support: Celgene Corporation. CC, MG, MW, JW; The authors declare that they have no competing interests.

\section{Authors' contributions}

$\mathrm{BC}$ interpreted the data, drafted the paper, and approved all versions including the final version. BB and JW acquired and analyzed the data, critically revised the paper, and approval all versions including the final version. $B P, H M P, F F, L S, F M, L P B, S P I, A S, T N, J N, S H, C C, M G, M W$ interpreted the data, critically revised the paper and approved all versions including the final version. All authors are responsible for the accuracy and integrity of all aspects of the manuscript.

\section{Acknowledgements}

The authors take full responsibility for the content of this manuscript, but thank Stacey Rose, PhD (MediTech Media), for providing medical editorial assistance. Financial support for medical editorial assistance was provided by Celgene Corporation. 


\section{Author details}

${ }^{1}$ Hospices Civils de Lyon, Lyon, France. ${ }^{2}$ Kimmel Cancer Center, Thomas Jefferson University, Philadelphia, PA, USA. ${ }^{3}$ Peter MacCallum Cancer Centre and University of Melbourne, Melbourne, Australia. ${ }^{4}$ Yale Cancer Center, New Haven, CT, USA. ${ }^{5}$ Moffitt Cancer Center, Tampa, FL, USA. ${ }^{6}$ Royal North Shore Hospital, Sydney, Australia. ${ }^{7}$ Hospital Universitario de Salamanca, Salamanca, Spain. ${ }^{8}$ Hôpital Claude Huriez, CHRU de Lille, Lille, France. ${ }^{9}$ Klinikum Nürnberg Nord, Nürnberg, Germany. ${ }^{10}$ UCLA Medical Center, Los Angeles, CA, USA. ${ }^{11}$ The Methodist Hospital, Houston, TX, USA. ${ }^{12}$ University of Washington, Seattle, WA, USA. ${ }^{13}$ Celgene Corporation, Summit, NJ, USA.

${ }^{14} \mathrm{JNich}$ ls LLC, Swampscott, MA, USA. ${ }^{15}$ Veristat, LLC, Holliston, MA, USA.

${ }^{16}$ Memorial Sloan-Kettering Cancer Center, New York, NY, USA.

Received: 26 November 2013 Accepted: 18 January 2014

Published: 23 January 2014

\section{References}

1. Foss FM, Zinzani PL, Vose JM, Gascoyne RD, Rosen ST, Tobinai K: Peripheral T-cell lymphoma. Blood 2011, 117(25):6756-6767.

2. Vose J, Armitage J, Weisenburger D, International T-Cell Lymphoma Project: International peripheral T-cell and natural killer/T-cell lymphoma study: pathology findings and clinical outcomes. J Clin Oncol 2008, 26(25):4124-4130.

3. Horwitz SM: Management of peripheral T-cell non-Hodgkin's lymphoma. Curr Opin Oncol 2007, 19(5):438-443.

4. Ascani S, Zinzani PL, Gherlinzoni F, Sabattini E, Briskomatis A, de Vivo A, Piccioli M, Fraternali Orcioni G, Pieri F, Goldoni A, et al: Peripheral T-cell lymphomas. Clinico-pathologic study of 168 cases diagnosed according to the R.E.A.L. classification. Ann Oncol 1997, 8(6):583-592.

5. Anderson JR, Armitage JO, Weisenburger DD: Epidemiology of the non-Hodgkin's lymphomas: distributions of the major subtypes differ by geographic locations. Non-Hodgkin's Lymphoma Classification Project. Ann Oncol 1998, 9(7):717-720.

6. Nakamura S, Koshikawa T, Koike K, Kitoh K, Suzuki H, Oyama A, Motoori T, Kojima M, Ogura M, Kurita S, et al: Phenotypic analysis of peripheral T cell lymphoma among the Japanese. Acta Pathol Jpn 1993, 43(7-8):396-412.

7. Rüdiger T, Weisenburger DD, Anderson JR, Armitage JO, Diebold MacLennan KA, Nathwani BN, Ullrich F, Müller-Hermelink HK: Peripheral T-cell lymphoma (excluding anaplastic large-cell lymphoma): results from the non-Hodgkin's Lymphoma Classification Project. Ann Oncol 2002, 13(1):140-149.

8. NCCN clinical practice guidelines in oncology: non-Hodgkin's lymphoma. 2nd edition. 2013.

9. Foss FM, Carson KR, Pinter-Brown L, Horwitz SM, Rosen ST, Pro B, Federico M, Gisselbrecht C, Hsi ED: Comprehensive oncology measures for peripheral T-cell lymphoma treatment (COMPLETE): first detailed report of primary treatment [abstract 1614]. Presented at: ASH Annual Meeting and Exposition; 2012.

10. Evens AM, Feldman T, Kroll A, Muffly LS, Winer E, Flowers C, Lansigan F, Nabhan C, Nastoupil L, Kim A, et al: Survival of newly diagnosed T-cell lymphoma (TCL) in the modern era: investigation of prognostic factors with critical examination of therapy in a multicenter US cohort [abstract 2728]. Presented at: ASH Annual Meeting and Exposition, December 8-11; 2012.

11. Reimer P: Impact of autologous and allogeneic stem cell transplantation in peripheral T-cell lymphomas. Adv Hematol 2010, 2010:320624.

12. Gutierrez A, Caballero MD, Perez-Manga G, Rodriguez J: Hematopoietic SCT for peripheral T-cell lymphoma. Bone Marrow Transplant 2008, 42(12):773-781.

13. Tan J, Cang S, Ma Y, Petrillo RL, Liu D: Novel histone deacetylase inhibitors in clinical trials as anti-cancer agents. J Hematol Oncol 2010, 3:5.

14. Bolden JE, Peart MJ, Johnstone RW: Anticancer activities of histone deacetylase inhibitors. Nat Rev Drug Discov 2006, 5(9):769-784.

15. Bradner JE, West N, Grachan ML, Greenberg EF, Haggarty SJ, Warnow T, Mazitschek R: Chemical phylogenetics of histone deacetylases. Nat Chem Biol 2010, 6(3):238-243.

16. ISTODAX (romidepsin) [package insert]. Summit, NJ: Celgene Corporation; 2013.

17. Coiffier B, Pro B, Prince HM, Foss F, Sokol L, Greenwood M, Caballero D, Borchmann $\mathrm{P}$, Morschhauser F, Wilhelm M, et al: Results from a pivotal, open-label, phase II study of romidepsin in relapsed or refractory peripheral T-cell lymphoma after prior systemic therapy. J Clin Oncol 2012, 30(6):631-636
18. FOLOTYN (pralatrexate) [package insert]: Westminster, CO: Allos Therapeutics, Inc; 2009.

19. Adcetris (brentuximab vedotin) [package insert]: Bothell, WA: Seattle Genetics, Inc; 2011

20. O'Connor OA, Pro B, Pinter-Brown L, Bartlett N, Popplewell L, Coiffier B, Lechowicz MJ, Savage KJ, Shustov AR, Gisselbrecht C, et al: Pralatrexate in patients with relapsed or refractory peripheral T-cell lymphoma: results from the pivotal PROPEL study. J Clin Oncol 2011, 29(9):1182-1189.

21. Pro B, Advani R, Brice P, Bartlett NL, Rosenblatt JD, Illidge T, Matous J, Ramchandren R, Fanale M, Connors JM, et al: Brentuximab vedotin (SGN-35) in patients with relapsed or refractory systemic anaplastic large-cell lymphoma: results of a phase II study. J Clin Oncol 2012, 30(18):2190-2196.

22. Pro B, Advani RH, Brice P, Bartlett NL, Rosenblatt JD, Illidge T, Matous JV, Ramchandren R, Fanale MA, Connors JM, et al: Long-term remissions observed in an ongoing phase 2 study of brentuximab vedotin in patients with relapsed or refractory systemic anaplastic large cell lymphoma [abstract 2745. Presented at: ASH Annual Meeting and Exposition, December 8-11; 2012.

23. Jacobsen ED, Advani RH, Oki Y, Sharman J, Horwitz SM, Forero-Torres A, O'Connor OA, Shustov AR, Siddiqi T, Grove LE, et al: A phase 2 study of brentuximab vedotin in patients with relapsed or refractory CD30-positive nonHodgkin lymphomas: interim results [abstract 2746]. Presented at: ASH Annual Meeting and Exposition, December 8-11; 2012.

24. Godfrey CJ, Cabell CH, Balser B, Wolfson J, Nichols J, Burris HA: Exposure-QTC response analysis of class 1 selective histone deacetylase inhibitor romidepsin. Presented at: ASH Annual Meeting and Exposition, December 10-13; 2011.

25. Petrich AM, Helenowski I, Galamaga RW, Nabhan C: Trends in incidence and outcome in T-cell lymphoma since 1992: A SEER database analysis [abstract 4264]. Presented at: ASH Annual Meeting and Exposition, December 8-11; 2012.

26. Flowers $C R$, Sinha $R$, Vose JM: Improving outcomes for patients with large B-cell lymphoma. CA Cancer J Clin 2010, 60:393-408.

27. Dupuis J, Casasnovas R, Ghesquieres H, Morschhauser F, Tilly H, Thieblemont C, Ribrag V, Coiffer B: A phase lb trial of romidepsin in association with CHOP in patients with peripheral T-cell lymphoma (PTCL): the ro-CHOP study [abstract 1617]. Presented at: ASH Annual Meeting and Exposition, December 8-11; 2012

28. Phase 3 multi-center randomized study to compare efficacy and safety of romidepsin CHOP (Ro-CHOP) versus CHOP in patients with previously untreated peripheral T-cell lymphoma. www.clinicaltrials.gov/ct2/show/NCT01796002. Accessed March 4, 2013.

29. Fanale MA, Shustov AR, Forero-Torres A, Bartlett NL, Advani RH, Pro B, Chen RW, Davies A, Illidge T, Kennedy DA, Horwitz SM: Combination chemotherapy and pralatrexate as first-line therapy in treating patients with non-Hodgkin lymphoma. Presented at: ASH Annual Meeting and Exposition, December $8-11 ; 2012$.

30. Combination chemotherapy and pralatrexate as first-line therapy in treating patients with non-Hodgkin lymphoma. www.clinicaltrials.gov/ct2/show/ NCT01336933. Accessed December 21, 2012.

31. Study of pralatrexate versus observation following CHOP-based chemotherapy in previously undiagnosed peripheral T-cell lymphoma patients. www. clinicaltrials.gov/ct2/show/NCT01420679. Accessed March 4, 2013.

32. Cheson BD, Horning SJ, Coiffier B, Shipp MA, Fisher RI, Connors JM, Lister TA, Vose J, Grillo-López A, Hagenbeek A, NCl sponsored International Working Group, et al: Report of an international workshop to standardize response criteria for non-Hodgkin's lymphomas. J Clin Oncol 1999, 17(4):1244.

33. Piekarz RL, Frye AR, Wright JJ, Steinberg SM, Liewehr DJ, Rosing DR, Sachdev V, Fojo T, Bates SE: Cardiac studies in patients treated with depsipeptide, FK228, in a phase II trial for T-cell lymphoma. Clin Cancer Res 2006, 12(12):3762-3773.

doi:10.1186/1756-8722-7-11

Cite this article as: Coiffier et al:: Romidepsin for the treatment of relapsed/refractory peripheral T-cell lymphoma: pivotal study update demonstrates durable responses. Journal of Hematology \& Oncology 2014 7:11. 